
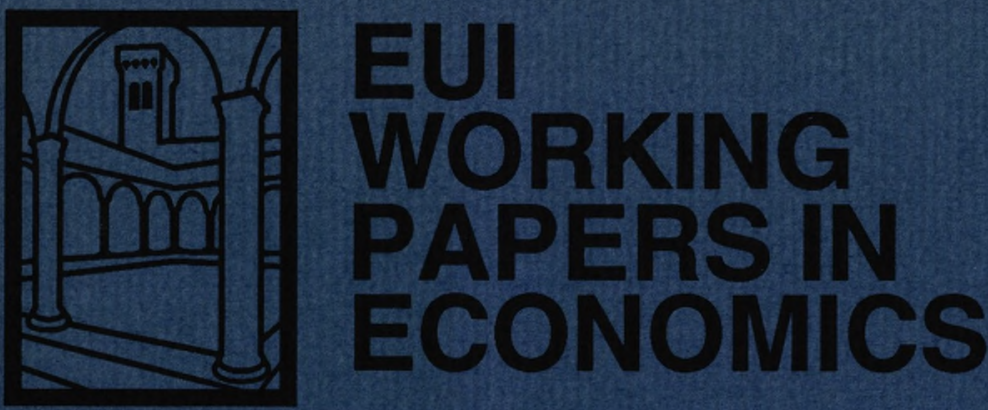

EUI Working Paper ECO No. 93/37

A Simple Message for Autocorrelation Correctors: DON'T

Grayham E. Mizon 
European University Library

|| ||||||||||||||||||||||||||||||||||||||||||||||||||||||||||||||||||||||

30001001513623

Please note

As from January 1990 the EUI Working Paper Series is divided into six sub-series, each sub-series is numbered individually (e.g. EUI Working Paper LA W No. 90/1). 


\section{EUROPEAN UNIVERSITY INSTITUTE, FLORENCE ECONOMICS DEPARTMENT}

EUI Working Paper ECO No. 93/37

A Simple Message for Autocorrelation Correctors: DON'T

GRAYHAM E. MIZON

BADIA FIESOLANA, SAN DOMENICO (FI) 
All rights reserved.

No part of this paper may be reproduced in any form without permission of the author.

(c) Grayham E. Mizon

Printed in Italy in December 1993

European University Institute

Badia Fiesolana

I - 50016 San Domenico (FI)

Italy 


\title{
A Simple Message for Autocorrelation Correctors: DON'T
}

\author{
Grayham E. Mizon \\ Economics Department, University of Southampton, \\ Southampton, UK. \\ $\&$ \\ Economics Department, European University Institute, \\ Florence, Italy.
}

First version June 1992, this revision November 1993.

\begin{abstract}
Though the practice of 'correcting for residual autocorrelation' has long been criticized it is still commonly advocated and followed. A simple example shows that even when a linear regression model has first order autoregressive errors it is possible for autoregressive least squares estimation (e.g. CochraneOrcutt) to yield inconsistent estimates. This dramatically illustrates that 'autocorrelation correction' is invalid in general, and cannot be justified on the grounds of 'robustifying' estimation against the presence of residual serial correlation. Invalid common factors in I(1) systems also have adverse effects on inference. A 'general-to-specific' modelling strategy applied to the observed modelled variables avoids these difficulties.
\end{abstract}

Address for Correspondence: Grayham E. Mizon, Economics Department, European University Institute, Badia Fiesolana, I-50016 San Domenico di Fiesole (FI), via dei Roccettini 9, Italy. 


\section{Introduction}

It is well known that the presence of serial correlation in the errors of a linear regression model induces problems for inference based solely on OLS methods. At the least, the OLS coefficient estimators will be inefficient and the corresponding standard errors incorrect, thus invalidating the conventional use of test statistics based on them. More seriously the OLS estimators will be biased and inconsistent in dynamic regression models. Hence it is important in econometric modelling to use residuals to test for the absence of serial correlation in the model errors. This is achieved easily now via the many test statistics which are included in econometrics and statistics software (e.g. those of Durbin and Watson (1950, 1951), Durbin (1970), and the more recent ones such as Breusch (1978) and Godfrey (1978), each of which are described in Engle (1984) and Godfrey (1990)). Indeed, it is now rare to find a piece of empirical economics using time series data that does not include a test for serial correlation. However, if the null hypothesis of no serial correlation is rejected there is not a unique alternative model to adopt, since all the test result has established is that the present model is inadequate, probably by having an inappropriate dynamic specification. Nevertheless, it remains a common practice to 'autocorrelation correct' the model by re-estimating it using one of the methods that assumes that the errors are generated by an autoregressive process e.g. by methods based on Cochrane-Orcutt (1949). This procedure has sometimes been justified on the grounds that, (i) it provides parameter estimates that are 'robust' to autocorrelated errors, and (ii) that it is appropriate to modify the original model in the direction of the alternative for which the test statistics used have high power. Neither of these putative justifications is valid in general, as has been argued by Sargan $(1964,1980)$, and inter alia Hendry and Mizon (1978), Hoover (1988), and Spanos (1988), and as the example in the next section dramatically illustrates.

The next section describes a bivariate process which has been used in PC-NAIVE [see Hendry, Neale and Ericsson (1990)] to generate a sample of size 100 to demonstrate that even when the regression error term is first order autoregressive, Au- 
toregressive Least Squares (ALS) estimation yields an inconsistent estimator of the regression coefficient. 'Autocorrelation correction' is one example of methods used in a 'specific-to-general' modelling strategy, which has been criticized by inter alia Mizon (1977a,b), Hendry (1983, 1987), and Hendry and Mizon (1990). The alternative strategy of following a general-to-specific approach to modelling avoids these problems, and is shown to work well for this example. In doing this the properties of the ALS estimator are compared with those of OLS estimators of the parameters of alternative models, and the encompassing abilities of these models are evaluated. In order to be sure that the results obtained using a single artificially generated sample are not overly peculiar to that sample, and also to assess the relevance of limiting distribution theory concerning the properties of the sample statistics used, results from a Monte Carlo simulation involving 10,000 replications are summarized. In view of the serious disadvantages that result from incorrectly imposing common factor restrictions section 3 contains an analysis of the structure of a linear stationary ergodic dynamic process, a characterization of the common factor restrictions, and discussion of some sufficient conditions for the common factor restrictions to hold. These sufficient conditions reveal that common factor restrictions are unlikely to be valid in general. An exception is the case in which the order of dynamics specified in a model is too large, so that the common factors correspond to zero roots. Section 4 demonstrates that difficulties also arise in the analysis of integrated variables when common factor restrictions are incorrectly imposed. These and other conclusions are contained in section 5 .

\section{2 'Autocorrelation Correction' Can Yield Incon- sistent Estimates: A Simple Example.}

An important part of designing econometric time series models to be congruent with the available information is to ensure that the class of model used is coherent with the time series properties of the sample data (see Hendry (1987), Hendry and Mizon (1990)). In order to illustrate the adverse consequences of not doing so Mizon (1993) used PC-NAIVE to generate data from the following data generating process (DGP): 


$$
\begin{aligned}
& y_{t}=\alpha y_{t-1}+\epsilon_{t} \\
& z_{t}=\eta_{t}
\end{aligned}
$$

with

$$
\left(\begin{array}{l}
\epsilon_{t} \\
\eta_{t}
\end{array}\right) \sim \mathrm{NI}\left(\left(\begin{array}{l}
0 \\
0
\end{array}\right),\left(\begin{array}{cc}
\sigma_{\epsilon}^{2} & \rho \\
\rho & \sigma_{\eta}^{2}
\end{array}\right)\right)
$$

when $\sigma_{\varepsilon}^{2}=\sigma_{\eta}^{2}=1, \alpha=0.5, \rho=0.9$, and the econometric sample size $T=100$. This DGP was chosen so that $y_{t}$ is serially dependent, and $z_{t}$ is serially independent, but they are correlated with each other. As a result the static linear regression model $\mathrm{M}_{1}$ :

$$
y_{t}=\beta_{1} z_{t}+u_{1 t}
$$

which relates $y_{t}$ to $z_{t}$ only, cannot be congruent since the error term $u_{1 t}$ must be serially correlated. This implies that $u_{1 t}$ contains valuable information for the modelling of $y_{t}$, namely lagged values of $y$ in this case. In fact, although the OLS estimator $\hat{\beta}_{1}$ is consistent for $\beta$, it is inefficient and the OLS standard errors are incorrect. This is illustrated by the following results, obtained from estimating $M_{1}$ for the data from replication 1000 of a Monte Carlo simulation run on PC-NAIVE using the DGP above $^{1}$. The full sample OLS estimates for the regression model $M_{1}$, with a constant term $c_{1}$ included, are:

$$
\begin{gathered}
\hat{y}_{t}=\begin{array}{cc}
-0.059 \\
{[0.079]}
\end{array} \\
R^{2}=0.619 \quad \begin{array}{c}
1.025 z_{t} \\
\hat{\sigma}_{1}=0.794
\end{array} \quad D W=0.915
\end{gathered}
$$

The figures in square brackets are heteroscedastic consistent standard errors, which nonetheless are inappropriate because of the residual serial correlation indicated by the DW statistic, and the $F$ form of the Lagrange multiplier first order serial correlation test statistic which has the value $F(1,97)=40.54$. However, as judged by a wide variety of other diagnostic test statistics there appear to be no further seri-

\footnotetext{
${ }^{1}$ Should anyone wish to reproduce these results the seed used for the random number generator was 980 .
} 
ous misspecifications. For example: $\operatorname{ARCH}(1,96)=1.590$ (with a p-value of 0.21 ), $\operatorname{Reset}(1,97)=1.913$ (with a p-value of 0.17$)$, normality $\chi^{2}(2)=0.343$, and the parameter constancy test statistics of Hansen (1991) based on the backward cumulative scores do not reject the hypothesis that $\sigma_{1}^{2}$ is constant (the variance instability test statistic $=0.157$ ), or the hypothesis that $\sigma_{1}^{2}$ and $\beta_{1}$ are constant (the joint instability test statistic $=0.728)$.

Mizon (1993) was concerned solely with an illustration of the consequences of using a noncongruent model. The emphasis in this paper is on the relative merits of alternative modelling strategies for responding to the finding that residuals are serially correlated. In particular, a comparison is made between, 'autocorrelation correction' until residuals appear to be white noise; robustification via semiparametric estimation; and the alternative of recommencing modelling by finding a congruent general model and then testing down using a general-to-specific strategy. Note that an important distinction between these procedures is that the first two adopt alternative estimation methods for a given model, whilst the third one embodies a modelling strategy which aims to find the simplest economically interpretable model that is congruent with the available information.

The precise nature of the serial correlation in $u_{1 t}$ is readily seen by adopting a reparameterization of equations (1) and (2). The distribution underlying (1) and (2) is $\mathrm{D}\left(y_{t}, z_{t} \mid y_{t-1}, z_{t-1} ; \boldsymbol{\theta}\right)$ with $\boldsymbol{\theta}^{\prime}=\left(\alpha, \rho, \sigma_{\epsilon}^{2}, \sigma_{\eta}^{2}\right)$, which can be reparameterized as $\mathrm{D}\left(y_{t} \mid z_{t}, y_{t-1}, z_{t-\mathbf{1}} ; \boldsymbol{\theta}_{1}\right) \times \mathrm{D}\left(z_{t} \mid y_{t-1}, z_{t-\mathbf{1}} ; \boldsymbol{\theta}_{2}\right)$ when $\boldsymbol{\theta}_{1}^{\prime}=\left(\alpha, \beta, \sigma_{\nu}^{2}\right)$ and $\boldsymbol{\theta}_{2}=\left(\sigma_{\eta}^{2}\right)$ with $\beta=\rho / \sigma_{\eta}^{2}$, and $\sigma_{\nu}^{2}=\sigma_{\epsilon}^{2}-\beta^{2} \sigma_{\eta}^{2}$ :

$$
\begin{gathered}
y_{t}=\beta z_{t}+\alpha y_{t-1}+\nu_{t} \\
z_{t}=\eta_{t} \\
\left(\begin{array}{l}
\nu_{t} \\
\eta_{t}
\end{array}\right) \sim \mathrm{NI}\left(\left(\begin{array}{l}
0 \\
0
\end{array}\right),\left(\begin{array}{cc}
\sigma_{v}^{2} & 0 \\
0 & \sigma_{\eta}^{2}
\end{array}\right)\right)
\end{gathered}
$$

Hence comparison of $M_{1}$ with (5) and (6) reveals that the population value of $\beta_{1}$ is $\beta$, and that the error term in $\mathrm{M}_{1}$ has the form $u_{1 t}=\alpha y_{t-1}+\nu_{t}$ which is serially correlated via $y_{t-1}$. The important question then is how in practice to respond to the indication of serially correlated errors for $M_{1}$. 


\subsection{Autocorrelation Correction.}

A common next step is to re-estimate $M_{1}$ assuming that the process generating the error $u_{1 t}$ is first order autoregressive. This is particularly the case if the parameter of interest is the partial response of $y_{t}$ to $z_{t}$, without being too careful about the specification of the information set relative to which this response is partial. Recent textbooks that present this approach as an appropriate reaction include: Berndt (1991, pp. 92, 281-2, 497, 567), Greene (1991, pp. 432-3), and Griffiths et al (1993, p536). On the other hand, Spanos (1986, pp.507-511) and Davidson and MacKinnon (1993, pp.364-369) are recent textbooks that clearly mention the dangers of imposing invalid common factor restrictions. The procedure of modifying the estimation method until the residuals appear to be white noise, is illustrated here by the following first order Autoregressive Least Squares (ALS(1)) estimates:

$$
\begin{aligned}
\hat{y}_{t}= & -0.066+0.741 z_{t}+0.707 \hat{u}_{1 t-1} \\
& (0.207) \quad(0.053) \quad(0.073)
\end{aligned}
$$

Although the equation standard error $\hat{\sigma}_{2}=0.602$ shows an improvement relative to the OLS estimates of $\mathbf{M}_{1}$, the ARCH(1) test statistic $F(1,95)=0.369$ (p-value 0.545) and the Jarque-Bera (1980) normality test statistic $\chi^{2}(2)=1.131$ indicate no apparent misspecification, the White (1980) heteroscedasticity test statistic calculated as $F(2,94)=4.341$ (p-value 0.016$)$ indicates a problem. Further, the residual correlogram suggests that there might be still some serial correlation in the residuals at lags 1,4 and 5 - an $F(5,88)=2.289$ (p-value 0.053 ) confirms that the hypothesis of the first five residual serial correlation coefficients being zero is not well supported.

More importantly, the point estimate of the coefficient of $z_{t}$ at 0.741 is a long way from the population value of $\beta=0.9$, and that of $\hat{u}_{1 t-1}$ at 0.707 a poor estimate of $\alpha=0.5$. Indeed, this $\operatorname{ALS}(1)$ estimator is biased and inconsistent for both $\alpha$ and $\beta$ in the context of the DGP given by (1) and (2). This can be seen by noting that on convergence the ALS(1) estimators of $\alpha$ and $\beta$ will (as a consequence of the biquadratic nature of the estimation criterion function - see Sargan (1964)) satisfy the following first order conditions simultaneously:

$$
\hat{\alpha}_{2}=\sum_{t=1}^{T}\left(y_{t}-\hat{\beta}_{2} z_{t}\right)\left(y_{t-1}-\hat{\beta}_{2} z_{t-1}\right) / \sum_{t=1}^{T}\left(y_{t-1}-\hat{\beta}_{2} z_{t-1}\right)^{2}
$$




$$
\hat{\beta}_{2}=\sum_{t=1}^{T}\left(y_{t}-\hat{\alpha}_{2} y_{t-1}\right)\left(z_{t}-\hat{\alpha}_{2} z_{t-1}\right) / \sum_{t=1}^{T}\left(z_{t}-\hat{\alpha}_{2} z_{t-1}\right)^{2}
$$

Hence denoting the pseudo true values of $\hat{\alpha}_{2}$ and $\hat{\beta}_{2}$ by $\alpha^{*}$ and $\beta^{*}$ respectively, and noting that from (5) and (6):

$$
\begin{gathered}
\left(y_{t}-\beta^{*} z_{t}\right)=\left(\beta-\beta^{*}\right) z_{t}+\alpha y_{t-1}+\nu_{t} \\
\left(y_{t}-\alpha^{*} y_{t-1}\right)=\beta z_{t}+\left(\alpha-\alpha^{*}\right) y_{t-1}+\nu_{t}
\end{gathered}
$$

it follows that $\alpha^{*}$ and $\beta^{*}$ must simultaneously satisfy:

$$
\begin{gathered}
\alpha^{*}=\alpha-\alpha \beta^{*}\left(\beta^{*}-\beta\right) /\left[\beta^{* 2}-2 \beta \beta^{*}+\sigma_{\epsilon}^{2} /\left(1-\alpha^{2}\right) \sigma_{\eta}^{2}\right] \\
\beta^{*}=\beta-\alpha \beta \alpha^{*} /\left(1+\alpha^{* 2}\right)
\end{gathered}
$$

Note that if $\alpha^{*}=\alpha$ then provided that $\alpha \neq 0$ (12) implies that $\beta^{*}=\beta$, but this is not a solution of (13) if $\beta \neq 0$. Equally, if $\beta^{*}=\beta$ then (12) implies that $\alpha=\alpha^{*}$, but this is only consistent with (13) if $\alpha=\alpha^{*}=0$. Hence whenever $\alpha \neq 0 \operatorname{ALS}(1)$ is inconsistent for both $\alpha$ and $\beta$. For the particular values of $\alpha, \beta, \sigma_{\epsilon}^{2}$ and $\sigma_{\eta}^{2}$ in the DGP given by (1) and (2) the real solutions of (12) and (13) are $\alpha^{*}=0.625$ and $\beta^{*}=0.698$ to three decimal places. ${ }^{2}$

The 'autocorrelation corrector' may, having noted the fact that the residuals still appear to be serially correlated, re-estimate $M_{1}$ allowing for second order autoregressive errors. Doing so yields the following results:

$$
\begin{array}{rlcc}
y_{t}= & -0.056+0.699 z_{t}+0.912 \hat{u}_{1 t-1}-0.274 \hat{u}_{1 t-2} \\
& (0.164) \quad(0.047) \quad(0.101) & (0.102)
\end{array}
$$

which has an equation standard error of $\hat{\sigma}_{A R 2}=0.587$ that appears to be a marginal improvement in goodness of fit relative to equation (7). Inspection of the residual correlogram for the $\operatorname{ALS}(2)$ estimates reveals no serious evidence of further serial

\footnotetext{
${ }^{2}$ In fact, substitution of (13) in (12) yields a $5^{\text {th }}$ order polynomial in $\alpha^{*}$ which has the following roots as solutions: $0.045 \pm 1.263,-0.108 \pm 0.700,0.625$ with $0.755 \pm$ $0.931,1.147 \pm 0.532,0.698$ the corresponding solutions for $\beta^{*}$.
} 
correlation, and the $\mathrm{ARCH}$, normality and parameter constancy test statistics yield no evidence of misspecification. In fact, had the 'autocorrelation corrector' continued as far as a fifth order autoregressive error process for $u_{1 t}$, the resulting ALS estimates would have revealed no need for autocorrelation correction beyond the second order. The statistics for testing the order of the autoregressive error process in Table 1 substantiate this point.

\section{Table 1: Test Statistics for AR errors. ${ }^{3}$}

\section{Order of AR Errors Number of Common Factors}

$\begin{array}{cccc}\text { Hypothesis } & \chi^{2}(1) & \text { Hypothesis } & \chi^{2}(1) \\ A R(4): A R(5) & 2.524 & r=1 & 0.129 \\ A R(3): A R(4) & 0.054 & r=2 & 0.250 \\ A R(2): A R(3) & 1.288 & r=3 & 0.645 \\ A R(1): A R(2) & 5.424 & r=4 & 3.537 \\ A R(0): A R(1) & 49.99 & r=5 & 65.63\end{array}$

The results given in the left hand side of Table 1 are likelihood ratio test statistics for hypotheses about the order of autoregressive error process AR(i-1) versus AR(i) for $i=1,2, \ldots 5$. Under the null hypothesis each of these test statistics has a limiting $\chi^{2}(1)$ distribution. The conclusion from this sequence of tests is that if $M_{1}$ is estimated by ALS then the order of autoregressive process needed is no larger than 2 . The estimated roots of the $\mathrm{AR}(2)$ polynomial are $0.456 \pm 0.132 i$, and the fact that they are complex may well be the reason for the rejection of the hypothesis that the order of the AR polynomial can be reduced to 1, given that common factors are imposed. Hence the 'autocorrelation corrector' after estimating $M_{1}$ by $\operatorname{ALS}(2)$, which results in the residuals appearing to be white noise, may believe that the estimated partial response of $y_{t}$ to $z_{t}$ at 0.699 is reliable, especially if there is no other conventional indication of model misspecification. However, this estimated coefficient of $z_{t}$ at 0.699 (with a standard error of 0.047 ) is a long way off $\beta=0.9$ ! The strategy of whitening the residuals by introducing higher and higher orders of residual autocorrelation

\footnotetext{
${ }^{3}$ These statistics were produced using PC-GIVE version 7 [see Doornik and Hendry (1992)].
} 
correction has failed to yield a consistent estimator of $\beta$, as it always will unless the implied common factor restrictions are satisfied.

The hypothesized behaviour of the 'autocorrelation corrector' above is an example of a series of moves from a specific to a more general model in response to indications of model misspecification. The sequence began with OLS estimation of $M_{1}$, and was followed by ALS(1), ALS(2) etc. of $\mathrm{M}_{1}$. In this particular case had the sequence of estimation and testing started from the model involving a fifth order autocorrelated error process and moved down to non-rejected lower orders, the selected model would still have been $M_{1}$ with $\mathrm{AR}(2)$ errors. Notice though, that the 'autocorrelation corrector' would have imposed common factor restrictions throughout, independently of their validity! The inappropriateness of $M_{1}$ with any order of autoregressive errors, will only be revealed if the common factor restrictions are tested.

The results given on the right hand side of Table 1 are incremental Wald test statistics for the hypothesis that $\mathrm{M}_{1}$, augmented by 5 lags of $y$ and $z$, has $r$ common factors for $r=1,2, \ldots .5$. Under the null hypothesis each of these test statistics has a limiting $\chi^{2}(1)$ distribution. The conclusion from this sequence of ordered tests is that there are 4 common factors. However, if following this conclusion $\mathrm{M}_{4}$ (see (15) below) were estimated by ALS(4) (this maintains 5 lags in the model, but with 4 common factors) the results would reveal that all 4 estimated serial correlation coefficients are not significantly different from zero. Thus, all 4 roots of the fourth order common factor polynomial are zero, which is not surprising given that $M_{3}$ (see (15) is the DGP. This provides an illustration of there being valid common factor restrictions as a result of common factors with zero roots being able to represent a model which contains redundant lags of all variables.

\subsection{Semiparametric Adjustment/Estimation.}

Another approach to the estimation of the response of $y_{t}$ to $z_{t}$ involves a mixture of parametric and nonparametric estimation, in which the OLS point estimate of $\beta$ and a heteroscedastic and autocorrelation consistent (HAC) estimator of its variance are calculated. Andrews (1991) and Newey and West (1987) inter alia propose and discuss alternative HAC estimators. Since the OLS estimator $\hat{\beta}_{1}$ is consistent for 
$\beta$ this "semiparametric" approach could be expected to achieve robust inference on the short run response of $y_{t}$ to $z_{t}$. A GAUSS programme was written implementing covariance matrix estimators discussed in Andrews (1991), and HAC estimates using four alternative kernels, and bandwidths in the range 1.0 to $10.0(=\sqrt{T})$, were generated. The results for a bandwidth of 1.0 are are given in Table 2 .

Table 2: Alternative Heteroscedastic-Autocorrelation Consistent

Estimates of $S E\left(\hat{\beta}_{1}\right)$.

\begin{tabular}{ll}
\multicolumn{2}{c}{ HAC Estimates } \\
kernel & $\frac{S E\left(\hat{\beta}_{1}\right)}{0.0741}$ \\
truncated & 0.0742 \\
Bartlett & 0.1049 \\
Parzen & 0.0742
\end{tabular}

In this case the HAC estimates are (with the exception of that from the Parzen kernel) very close to the population, sample, and Monte Carlo estimates using the standard OLS formula $V_{\text {ols }}\left(\hat{\beta}_{1}\right)=\sigma_{1}^{2}\left(X^{\prime} X\right)^{-1}$ - see Table 3 . However, the standard OLS formula is incorrect in this case, and should be replaced by $V\left(\hat{\beta}_{1}\right)=$ $\sigma_{1}^{2}\left(X^{\prime} X\right)^{-1} X^{\prime} A X\left(X^{\prime} X\right)^{-1}$ when $A=\left(a_{i j}\right)$ with $a_{i j}=\alpha^{|i-j|}$ for $i, j=1,2 \ldots . . T$. For the sample data $X$ generated by replication 1000 of the PC-NAIVE run, and the population parameter values $\alpha=0.5$ and $\sigma_{1}^{2}=0.5233, V\left(\hat{\beta}_{1}\right)=0.0061$ thus giving an estimated true standard error of $S E\left(\hat{\beta}_{1}\right)=0.0784$. Hence the semiparametric approach appears to be of limited value in this particular case where the essential problem with $M_{1}$ is that $u_{1 t}$ is not an innovation with respect to $y_{t-1}, z_{t}$ and $z_{t-1}$. Indeed, this approach lacks efficiency in general, and yields no information about the difference between the long run and short run responses of $y$ to $z$.

\subsection{General-to-Specific Modelling.}

An alternative strategy to either, attempting to "patch up" $M_{1}$ in a specific-to-general modelling strategy, or to using semiparametric estimation of $M_{1}$, is to acknowledge the inadequacy of $M_{1}$ and begin modelling again. This requires that a congruent 
general model be found, within which it will then be valid to test the parsimonious encompassing hypotheses for acceptable simplifications of it. Some of the models relevant in the present context are:

$$
\begin{aligned}
& \mathrm{M}_{1} \quad y_{t}=\beta_{1} z_{t}+u_{1 t} \\
& \mathrm{M}_{2} \quad y_{t}=\beta_{2} z_{t}+\alpha_{2} u_{1 t-1}+\epsilon_{2 t} \\
& \mathrm{M}_{3} \quad y_{t}=\beta_{3} z_{t}+\alpha_{3} y_{t-1}+u_{3 t} \\
& \mathrm{M}_{4} \quad y_{t}=\beta_{4} z_{t}+\alpha_{4} y_{t-1}+\gamma_{4} z_{t-1}+u_{4 t}
\end{aligned}
$$

Note that the scalars $\alpha, \beta$, and $\gamma$ are used for the coefficients of $y_{t-1}$ (or $u_{t-1}$ ), $z_{t}$, and $z_{t-1}$ respectively, with $\beta_{i}$ the coefficient of $z_{t}$ in $\mathrm{M}_{i}$ etc.. In addition, note that the most general model is $\mathrm{M}_{\mathbf{4}}$, so that if it is congruent it will be valid to test the ability of the remaining models to parsimoniously encompass it. To aid the understanding of these tests the population pseudo true values of the principal statistics associated with OLS estimation (ALS(1) for $M_{2}$ ) of these models have been calculated using the following formulae, and are given in Table 3. For the generic linear regression model $\mathbf{y}=X \boldsymbol{\beta}+\mathbf{u}=X \mathbf{b}+\mathbf{e}$ with $\mathbf{b}=\left(X^{\prime} X\right)^{-1} X^{\prime} \mathbf{y}$ the OLS estimator the population values were calculated as:

$$
\begin{gathered}
\tilde{\boldsymbol{\beta}}=\operatorname{plim}_{T \rightarrow \infty} \mathbf{b}, \\
R \tilde{S} S=T \operatorname{plim}_{T \rightarrow \infty}\left(\mathbf{e}^{\prime} \mathbf{e} / T\right)=T\left(V(y)-\tilde{\boldsymbol{\beta}}^{\prime} V(\mathbf{x}) \tilde{\boldsymbol{\beta}}\right), \\
\varphi=\operatorname{plim}_{T \rightarrow \infty}\left(\mathbf{e}^{\prime} \mathbf{e}_{-1} / \mathbf{e}^{\prime} \mathbf{e}\right), \\
D \tilde{W}=\operatorname{plim}_{T \rightarrow \infty} D W=2(1-\varphi), \\
\tilde{\sigma}^{2}=R \tilde{S} S /(T-k), \text { and } S \tilde{E}\left(\beta_{i}\right)=\tilde{\sigma} \sqrt{ }\left\{[V(\mathbf{x})]_{i i}^{-1}\right\},
\end{gathered}
$$

when $V(y)$ is the variance of $y$, and $V(\mathbf{x})$ is the variance-covariance matrix for $\mathbf{x}$. Note that for $\mathrm{M}_{2}$ the formula used for the calculation of the limiting variance-covariance matrix, and hence $S \tilde{E}\left(\beta_{2}\right)$, was that relevant for a misspecified model $\left(I^{-1} J I^{-1}\right)$ when $I$ is the information matrix and $J$ is the variance-covariance matrix of the score vector. In general $\tilde{\sigma}^{2}$ and $S \tilde{E}\left(\beta_{i}\right)$ calculated as defined above are calibrated for a sample of size $T$. 
Table 3: Model Characteristics.

$\begin{array}{ccccccccc} & \beta_{i} & S E\left(\hat{\beta}_{i}\right) & \alpha_{i} & S E\left(\hat{\alpha}_{i}\right) & \gamma_{i} & S E\left(\hat{\gamma}_{i}\right) & D W & \sigma_{i} \\ \mathrm{M}_{1} & & & & & & & & \\ P & 0.9 & 0.073 & 0 & n a & 0 & n a & 1.0 & 0.723 \\ S & 1.025 & 0.074 & 0 & n a & 0 & n a & 0.92 & 0.794 \\ M C & 0.893 & 0.072 & 0 & n a & 0 & n a & 1.03 & 0.714 \\ \mathrm{M}_{2} & & & & & & & & \\ P & 0.698 & 0.053 & 0.625 & 0.084 & 0 & n a & 1.84 & 0.586 \\ S & 0.741 & 0.053 & 0.707 & 0.073 & 0 & n a & n a & 0.602 \\ M C & 0.700 & 0.051 & 0.603 & 0.078 & 0 & n a & 1.81 & 0.583 \\ \mathrm{M}_{3} & & & & & & & & \\ P & 0.9 & 0.044 & 0.5 & 0.038 & 0 & n a & 2.0 & 0.436 \\ S & 0.952 & 0.045 & 0.516 & 0.035 & 0 & n a & 1.81 & 0.442 \\ M C & 0.900 & 0.044 & 0.495 & 0.039 & 0 & n a & 2.0 & 0.436 \\ \mathrm{M}_{4} & & & & & & & & \\ P & 0.9 & 0.044 & 0.5 & 0.060 & 0.0 & 0.070 & 2.0 & 0.436 \\ S & 0.952 & 0.046 & 0.548 & 0.057 & -0.05 & 0.074 & 1.85 & 0.445 \\ M C & 0.900 & 0.044 & 0.487 & 0.063 & 0.011 & 0.071 & 1.99 & 0.436\end{array}$

The rows labelled $\mathrm{P}, \mathrm{S}$ and $\mathrm{MC}$ report respectively the population value, the sample estimate based on the data for replication 1000 from PC-NAIVE, and the average value over 10,000 replications, for the parameter/statistic heading each column. The sample estimates were obtained using PC-GIVE version 7 [see Doornik and Hendry (1992)]. The Monte Carlo simulation results for $M_{1}, M_{3}$, and $M_{4}$ were generated using PC-NAIVE, and those for $\mathrm{M}_{2}$ using GAUSS. In generating the sample and Monte Carlo statistics intercepts were included in the regressions even though their population values are all zero. The estimates are not reported since none of the point estimates exceeded 0.001 and the smallest standard error was 0.04 . In the Monte Carlo study the following rejection frequencies were obtained for the $t$ statistics for the hypotheses: (i) $\beta=0,100 \%$; (ii) $\alpha=0,100 \%$; (iii) $\alpha=0.5, \simeq 5 \%$; (iv) $\gamma=0$, $100 \%$. 
Inspection of these population values reveals that OLS estimation applied to $M_{4}$ and $\mathrm{M}_{3}$ yields consistent estimators of $\alpha$ and $\beta$, and that $\mathrm{M}_{1}$ yields a consistent estimator of $\beta$. However, $M_{1}$ is variance dominated by the other models, and so it cannot encompass them. In addition, $M_{1}$ has serially correlated errors as noted above and indicated by the population value of the DW statistic. Although models $M_{3}$ and $\mathrm{M}_{4}$ each yield consistent estimators of $\alpha$ and $\beta$, and have population values of the DW statistic equal to $2.0, \mathrm{M}_{3}$ is the more efficient estimator. Whilst this is not surprising given that $M_{3}$ corresponds to the DGP defined in (1) and (2), it is only in the estimation of $\alpha$ that the efficiency gains are noticeable. Indeed, $z_{t}$ is strongly exogenous for $\beta$ in both $\mathrm{M}_{3}$ and $\mathrm{M}_{4}{ }^{4}$

In order to assess the congruence of each of these models in the sample Table 3 provides coefficient estimates and other statistics, using the data from replication 1000. Test statistics for $\mathrm{ARCH}(1)$, heteroscedasticity, normality, and functional form were also calculated for all four models, but are not reported since none was significant at conventional levels. The static long run response of $y$ to $z$, which in the DGP is given by $\beta /(1-\alpha)$, has a population value of 1.8. Models $M_{1}$ and $M_{2}$ restrict the long and short run responses to be equal, as a result of imposing common factor restrictions, and so yield bad point estimates of these responses.

\subsubsection{Direct Reductions of $M_{4}$.}

$\mathrm{M}_{\mathbf{4}}$, the most general model considered in Table 3, appears to be a congruent model on the basis of all the diagnostic test statistics calculated. It is therefore relevant, and valid to test for acceptable reductions of it. Statistics for testing the hypotheses that the other three models parsimoniously encompass $M_{4}$ are given in Figure 1, which also diagrammatically presents the relationship between the models.

\footnotetext{
${ }^{4}$ In fact, $\mathrm{E}\left[u_{3 t} z_{t}\right]=\mathrm{E}\left[u_{4 t} z_{t}\right]=\mathrm{E}\left[\nu_{t} z_{t}\right]=0$ and $y_{t}$ does not Granger-cause $z_{t}$ so that $z_{t}$ is strongly exogenous for $\alpha, \beta$ and the error variances in both $\mathrm{M}_{3}$ (the DGP) and $M_{4}$-see Engle, Hendry and Richard (1983). However, $z_{t}$ is not even weakly exogenous for $\alpha, \beta$ and $\sigma_{\epsilon_{2}}^{2}$ in $\mathrm{M}_{2}$, or for $\beta$ and $\sigma_{1}^{2}$ in $\mathrm{M}_{1}$. This is reflected in the fact that ALS estimation of $\mathrm{M}_{2}$ is inconsistent for $\alpha$ and $\beta$, and OLS estimation of $\mathrm{M}_{1}$ is inconsistent for $\alpha$ and $\sigma_{1}^{2}$, and inefficient though consistent for $\beta$.
} 


$$
M_{4}: y_{t}=\alpha y_{t-1}+\beta z_{t}+\gamma z_{t-1}+y_{t}=\alpha y_{t-1}+\beta\left[z_{t}-\alpha z_{t-1}\right]+[\gamma+\alpha \beta] z_{t-1}+z_{t}
$$

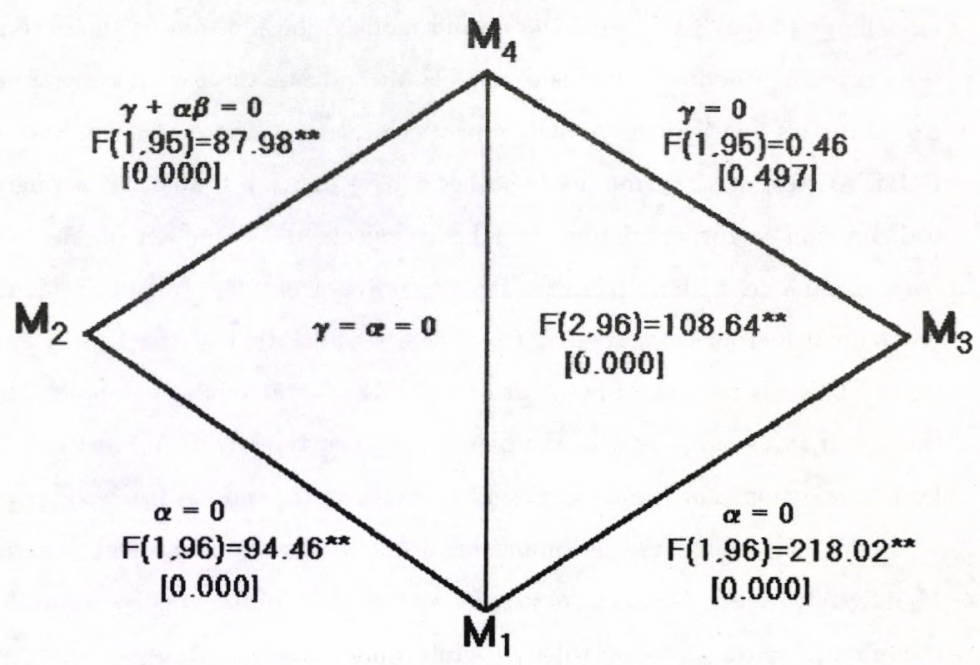

Figure 1: Parsimonious Encompassing Test Statistics 
The test statistics in Figure 1 were evaluated using the data from replication 1000 of the PC-NAIVE simulation study of the data generation process defined in (1) and (2). Also note that since the models considered are dynamic all the reported $F\left(n_{1}, n_{2}\right)$ statistics only have the $\mathrm{F}$ distribution asymptotically. Further, note that p-values are reported in square brackets below each test statistic, and ${ }^{* *}$ denotes that the test statistic rejects the null hypothesis at conventional significance levels.

The test statistics for the hypothesis that each of the models nested within $M_{4}$ parsimoniously encompass it, show that the only non-rejected reduction of $M_{4}$ is $M_{3}$ i.e. $M_{2} \mathcal{E}_{p} M_{4}$ and $M_{1} \mathcal{E}_{p} M_{4}$ are rejected but $M_{3} \mathcal{E}_{p} M_{4}$ is accepted. This result is both predictable from analysis of alternative parameterizations of the underlying DGP, and reassuring in that the use of sample test statistics within a general-to-specific modelling strategy can reveal the invalid models. In addition to the encompassing tests revealing the inadequacies of models $M_{1}$ and $M_{2}$, the parameter estimates and test statistics point to the probable misspecification of these models. Note that the COMFAC test statistic for the hypothesis $\left(\gamma_{4}+\alpha_{4} \beta_{4}\right)=0$ at 87.98 strongly rejects the common factor restriction, and hence rejects the reduction of $M_{4}$ to a static regression model with a first order autoregressive error $-\mathbf{M}_{2}$. In fact, in $\mathbf{M}_{4}$ the $y_{t}$ lag polynomial had an estimated root of 0.548 , whereas that of the $z_{t}$ polynomial was 0.053. There is no lack of power in the COMFAC test in this example! Manifestly though, if $\left(\gamma_{4}+\alpha_{4} \beta_{4}\right) \simeq 0$ in the population then the COMFAC test is unlikely to lead to rejection. For the DGP given by equations (1) and (2) $\left(\gamma_{4}+\alpha_{4} \beta_{4}\right)=0.45$.

Hence performing the encompassing tests within the congruent general model $M_{4}$ strongly rejects a static regression model with autoregressive error $M_{2}$, even though $u_{1 t}=\alpha u_{1 t-1}+w_{t}$ with $w_{t}$ white noise! Note that $u_{1 t}=\alpha y_{t-1}+\nu_{t}$ implies that $w_{t}=\alpha \beta z_{t-1}+\nu_{t}$ so that $w_{t}$ is white noise since $z_{t-1}$ and $\nu_{t}$ are mutually and serially uncorrelated, and has variance $\sigma_{w}^{2}=\sigma_{v}^{2}+\alpha^{2} \beta^{2} \sigma_{\eta}^{2}=0.393$. However, $\mathrm{E}\left[\left(z_{t}-\alpha z_{t-1}\right) w_{t}\right]=-\alpha^{2} \beta \sigma_{\eta}^{2} \neq 0$ and so even if $\alpha$ were known, and the quasidifferences $\tilde{y}_{t}=\left(y_{t}-\alpha y_{t-1}\right)$ and $\tilde{z}_{t}=\left(z_{t}-\alpha z_{t-1}\right)$ thus calculable, the Generalized Least Squares (GLS) estimator of $\beta$ in $M_{1}$ would be inconsistent.

Further insight can be obtained by reparameterizing $M_{2}$ as:

$$
\mathrm{M}_{2}:\left(y_{t}-\alpha^{*} y_{t-1}\right)=\beta^{*}\left(z_{t}-\alpha^{*} z_{t-1}\right)+\zeta_{t}
$$


in which

$$
\zeta_{t}=\nu_{t}+\left(\alpha-\alpha^{*}\right) y_{t-1}+\left(\beta-\beta^{*}\right) z_{t}+\alpha^{*} \beta^{*} z_{t-1}
$$

so that

$$
\begin{aligned}
\sigma_{\zeta}^{2} & =\left(1-2 \alpha \alpha^{*}+\alpha^{*^{2}}\right) V(y)+\left[\beta^{*^{2}}\left(1+\alpha^{*^{2}}\right)-2 \beta \beta^{*}\left(1-\alpha \alpha^{*}+\alpha^{*^{2}}\right)\right] \sigma_{\eta}^{2} \\
& =0.344
\end{aligned}
$$

and

$$
\mathrm{E}\left[\left(z_{t}-\alpha^{*} z_{t-1}\right) \zeta_{t}\right]=\left[\left(\beta-\beta^{*}\right)\left(1+\alpha^{* 2}\right)-\alpha^{*} \alpha \beta\right] \sigma_{\eta}^{2}=0
$$

since $\left(\beta-\beta^{*}\right)\left(1+\alpha^{* 2}\right)=\alpha^{*} \alpha \beta$ from (13). This is a consequence of ALS(1) being consistent for $\left(\alpha^{*}, \beta^{*}\right)$, but not for $(\alpha, \beta)$. Therefore, although $u_{1 t}$ in $\mathrm{M}_{1}$ follows a first order autoregressive process $u_{1 t}=\alpha u_{1 t-1}+w_{t}$ with $w_{t}$ white noise, and $z_{t}$ is strongly exogenous for $\beta$ in the DGP, ALS estimation of $M_{1}$ is inconsistent. In fact, $w_{t}$ despite being white noise is not an innovation with respect to the information set including $y_{t-1}, z_{t}$, and $z_{t-1}{ }^{5}$ :

$$
\mathrm{E}\left[y_{t-1} w_{t}\right]=\alpha \beta^{2} \sigma_{\eta}^{2} \quad \mathrm{E}\left[z_{t} w_{t}\right]=0 \quad \mathrm{E}\left[z_{t-\imath} w_{t}\right]=\alpha \beta \sigma_{\eta}^{2}
$$

On the other hand, although $\zeta_{t}$ has a smaller variance than $w_{t}$, and is orthogonal to $\left(z_{t}-\alpha^{*} z_{t-1}\right)$, it is not an innovation with respect to $y_{t-1}, z_{t}$, and $z_{t-1}$ :

$$
\begin{aligned}
& \mathrm{E}\left[y_{t-1} \zeta_{t}\right]=\left(\alpha-\alpha^{*}\right) V(y)+\alpha^{*} \beta^{*} \beta \sigma_{n}^{2} \\
& \mathrm{E}\left[z_{t} \zeta_{t}\right]=(\beta-\beta *) \sigma_{\eta}^{2} \\
& \mathrm{E}\left[z_{t-1} \zeta_{t}\right]=\left[\left(\alpha-\alpha^{*}\right) \beta+\alpha^{*} \beta *\right] \sigma_{\eta}^{2} .
\end{aligned}
$$

Further, noting that $\zeta_{t}$ is $\epsilon_{2 t}$ with $\alpha_{2}$ and $\beta_{2}$ replaced by the pseudo true values of their ALS(1) estimators, it is clear from (17) that $\zeta_{t}$ and hence $\epsilon_{2 t}$ are serially correlated.

${ }^{5}$ Granger (1983) contains an illuminating discussion of the difference between white noise and innovation random variables. 


\subsubsection{Sequential Reductions of $M_{4}$.}

An alternative testing procedure uses the fact that the models form ordered nests within $M_{4}$, which is in fact over-parameterized relative to the DGP. The Incremental Tests in Figure 1 involve the test statistics for the sequence of hypotheses: (i) $\left(M_{3} \mathcal{E}_{p} M_{4}\right)$ and $\left(M_{1} \mathcal{E}_{p} M_{3}\right)$ and (ii) $\left(M_{2} \mathcal{E}_{p} M_{4}\right)$ and $\left(M_{1} \mathcal{E}_{p} M_{2}\right)$. These test statistics reveal that the sequential reduction $M_{4} \rightarrow M_{3}$ is not rejected, but that the further reduction $M_{3} \rightarrow M_{1}$ is strongly rejected. On the other hand the reduction $M_{4} \rightarrow M_{2}$ is strongly rejected and so the further reduction $M_{2} \rightarrow M_{1}$ is not relevant. In fact, given that $M_{4} \mathcal{E}_{p} M_{2}$ is rejected so that $M_{2}$ is not congruent, the test of $M_{1} \mathcal{E}_{p} M_{2}$ is invalid. However, despite $M_{2}$ being noncongruent, $\beta^{*}=\beta$ when $\alpha^{*}=0$ from (12) and (13) so that under $M_{2}$ with $\alpha^{*}=0$ the $\operatorname{plim}_{T \rightarrow \infty} \hat{\beta}_{1}=\beta$ which is consistent with a nesting model always encompassing a model nested within it $-M_{2} \mathcal{E} M_{1}$ in this case. Therefore, the incremental tests also perform well for this example, leading to $M_{3}$ as the simplest non-rejected reduction of $\mathrm{M}_{4}$.

The only models listed above that will yield consistent estimates of $\beta$ are $M_{1}, M_{3}$ and $M_{4}$. However, $M_{1}$ has serially correlated errors, is variance dominated by both $M_{3}$ and $M_{4}$, and $M_{3} \mathcal{E}_{p} M_{4}$. Therefore, the most efficient estimate of $\beta$ comes from $M_{3}$. These theoretical results are closely matched by the sample statistics and the Monte Carlo simulation results reported in Table 3 . The figures reported under the heading Monte Carlo are the average across 10,000 replications of the values of the calculated statistics associated with the estimation of the models. In fact, for $M_{1}, M_{3}$ and $M_{4}$ the Monte Carlo estimates are extremely close to the population values for all statistics. The same is true for $\mathrm{M}_{2}$, except for the estimator of $\alpha_{2}$ where there is evidence in the sample and the Monte Carlo estimates of the small sample Hurwicz (1950) bias $\left(-\frac{2 \alpha}{T}=-0.01\right)$. Hence there is close agreement between the asymptotic theory, the sample estimates $(T=100)$, and the Monte Carlo estimates, for the particular point in parameter space represented by (1) and (2).

\section{The Structure of Common Factor Restrictions.}

Given the results in the previous section showing that inconsistent parameter estimates, and misleading inferences generally, can result from imposing invalid common 
factor restrictions, this section analyses the nature of these restrictions for general stationary processes in order to assess how likely it is that they will be valid in practice.

Consider a stationary ergodic process $\left\{\mathbf{x}_{t}\right\}$ for which $\mathbf{x}_{t}^{\prime}=\left(y_{t}, \mathbf{z}_{t}^{\prime}\right)$ with $\mathbf{z}_{t}$ a $k \times 1$ vector, and without loss of generality let $\mathrm{E}\left[\mathrm{x}_{t}\right]=0 \forall t$ and

$$
\mathrm{E}\left[\mathbf{x}_{t} \mathbf{x}_{s}^{\prime}\right]=\Omega\left(||_{t-s} \mid\right)=\left(\begin{array}{ll}
\Omega_{y y}(i) & \Omega_{y z}(i) \\
\Omega_{z y}(i) & \Omega_{z z}(i)
\end{array}\right)=\left(\begin{array}{ll}
\Omega_{x y}(i) & \Omega_{x z}(i)
\end{array}\right)
$$

for $i=|t-s|$ so that:

$$
\Omega(i)^{-1}=\left(\begin{array}{ll}
\Omega^{y y}(i) & \Omega^{y z}(i) \\
\Omega^{z y}(i) & \Omega^{z z}(i)
\end{array}\right)=\left(\begin{array}{ll}
\Omega^{x y}(i) & \Omega^{x z}(i)
\end{array}\right)
$$

To simplify the subsequent analysis with a relatively unimportant loss of generality it is assumed that the $\left\{x_{t}\right\}$ process is first order Markov, so that $\mathrm{D}\left(\mathbf{x}_{t} \mid X_{t-1}\right)=$ $\mathrm{D}\left(\mathbf{x}_{t} \mid \mathbf{x}_{t-1}\right)$ when $X_{t-1}=\left(\ldots . \mathbf{x}_{-1}, \mathbf{x}_{0}, \mathbf{x}_{1}, \ldots . \mathbf{x}_{t-1}\right)$ and has the form:

$$
\mathbf{x}_{t} \mid \mathbf{x}_{t-1} \sim \mathbf{N}\left(\Pi_{x x} \mathbf{x}_{t-1}, \Sigma_{x x}\right)
$$

with

$$
\Pi_{x x}=\Omega_{x x}(1) \Omega_{x x}(0)^{-1}
$$

and

$$
\Sigma_{x x}=\Omega_{x x}(0)-\Omega_{x x}(1) \Omega_{x x}(0)^{-1} \Omega_{x x}(1)=\Omega_{x x}(0)-\Pi_{x x} \Omega_{x x}(0) \Pi_{x x}^{\prime} .
$$

Higher order systems could be transformed into this first order form by use of the companion form representation [see Hendry and Mizon (1993) for a recent example]. Further, $\mathrm{D}\left(\mathbf{x}_{t} \mid \mathbf{x}_{t-1}\right)$ can be factored into $\mathrm{D}\left(y_{t} \mid \mathbf{z}_{t}, \mathbf{x}_{t-1}\right) \times \mathrm{D}\left(\mathbf{z}_{t} \mid \mathbf{x}_{t-1}\right)$ when $\mathbf{x}_{t}^{\prime}$ is partitioned into $\left(y_{t}, \mathbf{z}_{t}^{\prime}\right)$ with $\Pi_{x x}$ and $\Sigma_{x x}$ being similarly partitioned. The corresponding densities are:

$$
\begin{gathered}
y_{t} \mid \mathbf{z}_{t}, \mathbf{x}_{t-1} \sim \mathrm{N}\left(\alpha y_{t-1}+\boldsymbol{\beta}^{\prime} \mathbf{z}_{t}+\gamma^{\prime} \mathbf{z}_{t-1}, \sigma^{2}\right) \\
\mathbf{z}_{t} \mid \mathbf{x}_{t-1} \sim \mathrm{N}\left(\Pi_{y y} y_{t-1}+\Pi_{z z} \mathbf{z}_{t-1}, \Sigma_{z z}\right)
\end{gathered}
$$

with:

$$
\alpha=\Pi_{y y}-\boldsymbol{\beta}^{\prime} \Pi_{z y}, \boldsymbol{\beta}^{\prime}=\Sigma_{y z} \Sigma_{z z}^{-1}, \boldsymbol{\gamma}^{\prime}=\Pi_{y z}-\boldsymbol{\beta}^{\prime} \Pi_{z z}, \sigma^{2}=\Sigma_{y y}-\boldsymbol{\beta}^{\prime} \Sigma_{z z} \boldsymbol{\beta}
$$


Let $\boldsymbol{\lambda}_{1}^{\prime}=\left(\alpha, \boldsymbol{\beta}^{\prime}, \boldsymbol{\gamma}^{\prime}, \sigma^{2}\right)$ and $\boldsymbol{\lambda}_{2}^{\prime}=\left(\Pi_{z y}, \operatorname{vec}\left(\Pi_{z z}\right)^{\prime}\right.$, vech $\left.\left(\Sigma_{z z}\right)^{\prime}\right)$. Then assuming that the parameters of interest $\boldsymbol{\psi}$ are solely functions of $\boldsymbol{\lambda}_{1}$ and that $\boldsymbol{\lambda}_{1}$ and $\boldsymbol{\lambda}_{2}$ are variation free, ensures that $z_{t}$ is weakly exogenous for $\boldsymbol{\psi}$, and so efficient inference on $\boldsymbol{\psi}$ can be made from $\mathrm{D}\left(y_{t} \mid \mathbf{z}_{t}, \mathbf{x}_{t-1}\right)$ alone [see Engle, Hendry and Richard (1983)]. The relationship between the parameters of the conditional model $\mathrm{D}\left(y_{t} \mid \mathbf{z}_{t}, \mathbf{x}_{t-1}\right)$ and those of the underlying Markov process (or VAR) D $\left(\mathbf{x}_{t} \mid \mathbf{x}_{t-1}\right)$ is given by:

$$
\boldsymbol{\beta}=\left[\Omega_{z z}(0)-\Omega_{z x}(1) \Omega^{x x}(0) \Omega_{x z}(1)\right]^{-1}\left[\Omega_{z y}(0)-\Omega_{z x}(1) \Omega^{x x}(0) \Omega_{x y}(1)\right]
$$

and:

$$
\begin{gathered}
\boldsymbol{\gamma}^{\prime}=\boldsymbol{\delta}^{\prime} \Omega_{x x}(1) \Omega^{x z}(0)=\boldsymbol{\delta}^{\prime} \Pi_{x z} \\
\alpha=\boldsymbol{\delta}^{\prime} \Omega_{x x}(1) \Omega_{x x}(0)^{-1} \boldsymbol{\delta}=\Pi_{y y}-\boldsymbol{\beta}^{\prime} \Pi_{z y}=\boldsymbol{\delta}^{\prime} \Pi_{x y} \\
\sigma^{2}=\boldsymbol{\delta}^{\prime} \Sigma_{x x} \boldsymbol{\delta}
\end{gathered}
$$

when $\boldsymbol{\delta}^{\prime}=\left(1,-\boldsymbol{\beta}^{\prime}\right)$ so that $\boldsymbol{\beta}^{\prime}=\boldsymbol{\delta}^{\prime} P$ with $P^{\prime}=\left(0,-I_{k}\right)$.

Therefore the dynamics of the conditional model $\mathrm{D}\left(y_{t} \mid \mathbf{z}_{t}, \mathbf{x}_{t-1}\right)$ will be represented entirely by an autoregressive error process if and only if the following common factor hypothesis $\mathrm{H}_{0}$ holds:

$$
\mathrm{H}_{0}: \boldsymbol{\gamma}+\alpha \boldsymbol{\beta}=\Pi_{x z}^{\prime} \delta+\beta \Pi_{x y}^{\prime} \delta=\left[\Pi_{x z}^{\prime}+\beta \Pi_{x y}^{\prime}\right] \delta=0
$$

or:

$$
\mathrm{H}_{0}: Q^{\prime} \Pi_{x x}^{\prime} \delta=0
$$

when $Q^{\prime}=\left(I_{k}, P^{\prime} \boldsymbol{\delta}\right)=\left(I_{k}, \boldsymbol{\beta}\right)$. The fact that the common factor restrictions are nonlinear is reflected in the dependence of $Q$ on $\delta$, and hence $\boldsymbol{\beta}$. Although these necessary and sufficient conditions are nonlinear functions of the underlying parameters of the VAR model only (namely $\Pi_{x x}$ and $\Sigma_{x x}$ ) they cannot be written as simpler functions of them. However, a number of sets of sufficient conditions are easily obtained.

Sufficient Conditions for $\mathrm{H}_{0}$ : 
(i) $\Pi_{x x}=0$ so that there are no dynamics in the system, and the common factors correspond to zero roots in the system.

(ii) $\Pi_{x x} \delta=\left(\Pi_{x z}^{\prime} \delta, \Pi_{x y}^{\prime} \delta\right)=0$. This restriction is identical to $\gamma=0$ and $\alpha=0$, so that there are no dynamics in the conditional model, and the common factors correspond to zero roots in the conditional model $\mathbf{D}\left(y_{t} \mid \mathbf{z}_{t}, y_{t-1}, \mathbf{z}_{t-1}\right)$.

(iii) $\Pi_{x x}=\Pi_{y y} I_{n}$ when $n=k+1$. This means that $y$ and $\mathbf{z}$ are mutually Granger-noncausal and that $\mathbf{z}_{t}$ has essentially the same temporal structure as $y_{t}$, since $\Pi_{x x}=\Omega_{x x}(1) \Omega_{x x}(0)^{-1}=\Pi_{y y} I_{n}$ implies that $\Omega_{x x}(1)=\Pi_{y y} \Omega_{x x}(0)$ and all the variables are mutually Granger-noncausal - see Spanos (1988).

(iv) $\boldsymbol{\delta}^{\prime}=(1,0)$ and $\Pi_{y z}=0$ which implies that $\boldsymbol{\beta}=0$ and $\boldsymbol{\gamma}=0$. In this case $Q^{\prime} \Pi_{x x}^{\prime} \delta=Q^{\prime} \Pi_{y x}^{\prime}=\Pi_{y z}^{\prime}=0$, so that $y_{t}$ is unrelated to $\mathbf{z}_{t}$ or its lags, though $y$ can still Granger-cause $\mathbf{z}_{t}$. The particularly restrictive nature of this model is seen by noting that the VAR takes the following form in this case:

$$
\left(\begin{array}{l}
y_{t} \\
\mathbf{z}_{t}
\end{array}\right)=\left(\begin{array}{cc}
\Pi_{y y} & 0 \\
\Pi_{z y} & \Pi_{z z}
\end{array}\right)\left(\begin{array}{c}
y_{t-1} \\
\mathbf{z}_{t-1}
\end{array}\right)+\left(\begin{array}{c}
v_{1 t} \\
\boldsymbol{\nu}_{2 t}
\end{array}\right)
$$

with

$$
\left(\begin{array}{l}
v_{1 t} \\
\boldsymbol{\nu}_{2 t}
\end{array}\right) \sim \mathrm{NI}\left(\left(\begin{array}{l}
0 \\
0
\end{array}\right),\left(\begin{array}{cc}
\Sigma_{y y} & 0 \\
0 & \Sigma_{z z}
\end{array}\right)\right)
$$

Hence $y_{t}$ is generated by a purely autoregressive process, unaffected by the process generating $\mathbf{z}_{t}$, though it can Granger-cause $\mathbf{z}_{t}$.

For economic time series each of these sets of sufficient conditions is very restrictive and unlikely to hold in practice. Indeed, it does seem that for linear stationary ergodic systems the common factor restriction embodied in $\mathrm{H}_{0}$ is nothing more than a 'convenient simplification' when it is valid - see Hendry and Mizon (1978). However, many of the points made above about the adverse consequences of imposing invalid common factor restrictions still apply for non-stationary systems. In addition, since many economic time series are now analyzed within an integrated-cointegrated framework, the next section contains comments on common factor restrictions in such systems. 


\section{Common Factor Restrictions in Integrated Sys- tems.}

Following the influential work of Box and Jenkins (1970) and Granger and Newbold (1974) much more attention was paid to the time series properties of data by econometricians. In particular, the possibility that a nonstationary variable might be rendered stationary by a difference transformation was, and still is, often exploited. Hendry and Mizon (1978) pointed out such difference transformations in a multivariate context are particular examples of common factor restrictions, and argued the case for testing the validity of these restrictions rather than imposing them untested. Their further argument, that differencing variables prior to modelling the relationship between them means that potentially valuable long run or zero frequency information is ignored, was strengthened greatly by Granger's proposal of the concept of cointegration [see Granger (1981) and Engle and Granger (1987)]. There is now an enormous and growing literature on integration and cointegration - Banerjee et al (1993) provide an excellent review of it. The importance of the analysis of integration and cointegration in both theoretical and applied econometrics, justifies drawing attention to the consequences of imposing invalid common factor restrictions in this context and especially in the testing for unit roots.

\subsection{Univariate Unit Roots}

When $y_{t}$ and $\mathbf{z}_{t}$ are I(1) the relationship $y_{t}=\boldsymbol{\beta}^{\prime} \mathbf{z}_{t}+u_{t}$ will only have an error $u_{t}$ which is $\mathrm{I}(0)$ if $y_{t}$ and $\mathbf{z}_{t}$ cointegrate. A common test for cointegration between $y_{t}$ and $z_{t}$ is to test whether the OLS residuals:

$$
\hat{u}_{t}=y_{t}-\hat{\boldsymbol{\beta}}^{\prime} \mathbf{z}_{t}
$$

have a unit root - the hypothesis of cointegration being rejected if the unit root hypothesis is not rejected. Perhaps the most popular univariate unit root test procedure is that due to Dickey and Fuller $(1979,1981)$ in which the regression

$$
\Delta \hat{u}_{t}=\delta \hat{u}_{t-1}+\xi_{t}
$$


is used to test the hypothesis $\delta=0$ by comparing the $t_{(\delta=0)}$ statistic with critical values from the Dickey-Fuller distribution. Note that (33) and (34), with $\hat{\boldsymbol{\beta}}$ replaced by $\boldsymbol{\beta}$, imply:

$$
\Delta y_{t}=\boldsymbol{\beta}^{\prime} \Delta \mathbf{z}_{t}+\delta\left(y_{t-1}-\boldsymbol{\beta}^{\prime} \mathbf{z}_{t-1}\right)+\xi *_{t}
$$

which can be rearranged as:

$$
y_{t}=(1+\delta) y_{t-1}+\boldsymbol{\beta}^{\prime}\left(\mathbf{z}_{t}-(1+\delta) \mathbf{z}_{t-1}\right)+\xi *_{t}
$$

from which it is clear that $(36)$ has a common factor of $[1-(1+\delta) L]$. Thus the Dickey-Fuller (DF) and the various forms of Augmented DF test procedures impose an untested common factor and then test whether this common factor has a unit root. Not surprisingly, this procedure has been shown to lack power when the common factor restriction is invalid [see Kremers et al (1992)]. A further complication with the DF and ADF procedures arises from their use of two-stage estimation: (i) OLS estimation of $\boldsymbol{\beta}$ assuming that $\delta=0$; followed by (ii) OLS estimation of $\delta$ conditional on $\boldsymbol{\beta}=\hat{\boldsymbol{\beta}}$. Although the procedure is justified on the grounds that $\hat{\boldsymbol{\beta}}$ is superconsistent, this does not ensure good properties in small samples [see Banerjee et al (1986) and the further results in Banerjee et al (1993)].

An alternative test for cointegration between $y_{t}$ and $\mathbf{z}_{t}$, which does not have these drawbacks, is based on the error correction model (ECM). Assuming for simplicity that a model with first order dynamics:

$$
y_{t}=\alpha y_{t-1}+\boldsymbol{\beta}^{\prime} \mathbf{z}_{t}+\gamma^{\prime} \mathbf{z}_{t-1}+\omega_{t}
$$

provides an adequate representation of the relationship between $y_{t}$ and $\mathrm{z}_{t}$, then a re-parameterization yields the ECM:

$$
\Delta y_{t}=\boldsymbol{\beta}^{\prime} \Delta \mathbf{z}_{t}-(1-\alpha)\left(y_{t-1}-\boldsymbol{\kappa}^{\prime} \mathbf{z}_{t-1}\right)+\omega_{t}
$$

when $\boldsymbol{\kappa}=(1-\alpha)^{-1}(\boldsymbol{\gamma}+\boldsymbol{\beta})$ is the long run static response of $y$ to $\mathbf{z}$. Note that in general $\boldsymbol{\kappa}$ differs from $\boldsymbol{\beta}$ the instantaneous short run response of $y_{t}$ to $\mathbf{z}_{t}$, since the common factor restriction $(\boldsymbol{\gamma}+\alpha \boldsymbol{\beta})=\mathbf{0}$ has not been imposed. If $y_{t}$ and $\mathbf{z}_{t}$ are cointegrated with cointegrating vector $(1,-\boldsymbol{\kappa})$ then $\left(y_{t-1}-\boldsymbol{\kappa}^{\prime} \mathbf{z}_{t-1}\right), \Delta y_{t}$ and $\Delta \mathbf{z}_{t}$ 
are all I (0), so that $\omega_{t} \sim \mathrm{I}(0)$ even with $\alpha \neq 1$. Kremers et al (1992), Banerjee et al (1993) and Campos et al (1993) each present theoretical and Monte Carlo results that imply that $t_{(c=0)}$ in the rearranged ECM:

$$
\Delta y_{t}=\boldsymbol{\beta}^{\prime} \Delta \mathbf{z}_{t}+c\left(y_{t-1}-\mathbf{z}_{t-1}\right)+\omega *_{t}
$$

with $c=(\alpha-1), \omega_{t} *=\omega_{t}+c(\mathbf{i}-\boldsymbol{\kappa})^{\prime} \mathbf{z}_{t-1}$ and $\mathbf{i}$ a $k \times 1$ vector of unit elements, is a preferable test of cointegration to the DF (ADF) $t_{(\delta=0)}$. In particular, $t_{(c=0)}$ has a distribution under the null of no cointegration (i.e. $c=0$ ) which is well approximated by $\mathrm{N}(0,1)$, and under the alternative of cointegration has higher power than the DF $(\mathrm{ADF}) t_{(\delta=0)}$ statistic provided that $\frac{c^{2}}{\sigma^{2}}(\mathrm{i}-\kappa)^{\prime} \Sigma_{z z}(\mathrm{i}-\kappa)$ is sufficiently large. Campos et al (1993) conclude: 'When conditioning is valid, Dickey-Fuller statistics used to test for cointegration have no particular advantage over their ECM counterparts; and there is much to gain from using the latter when the common factor restriction is invalid'. Hence there are clear disadvantages to using univariate unit root test statistics that impose potentially invalid common factor restrictions - a point that applies more widely than just to the DF and ADF test statistics.

\subsection{Multivariate Unit Roots}

If in the $n$ dimensional system (21) $\mathbf{x}_{t} \sim \mathrm{I}(1)$ then there are two important cases in which $\epsilon_{t} \sim \mathrm{I}(0)$.

(i) $\operatorname{rank}\left(\Pi_{x x}-I_{n}\right)=v<n(=k+1)$ so that the system has $v$ cointegrating vectors and $(n-v)$ driving variables or common trends. In this case the system has $(n-v)$ unit roots and the ML procedure of Johansen (1988) provides a multivariate unit root test based on the ECM:

$$
\Delta \mathbf{x}_{t}=\left(\Pi_{x x}-I_{n}\right) \mathbf{x}_{t-1}+\epsilon_{t}
$$

to determine the value of $v$, which thus does not impose a common factor of $\Delta$ on all variables but tests the validity of this representation.

(ii) If $v=0$ then $\Pi_{x x}=I_{n}$ so that (21) becomes:

$$
\Delta \mathbf{x}_{t}=\epsilon_{t}
$$


which means that $\mathbf{x}_{t}$ is a multivariate $\mathrm{I}(1)$ process with no cointegration. In such a system each variable has a common factor of $\Delta$, and there are no stable relationships between the elements of $\mathbf{x}_{t}$. Note further that the conditional models derived from (41) will have $\Delta$ as a common factor. The fact that (41) is a restricted version of (40) and it implies that there are only stable relationships among the changes $\Delta \mathbf{x}_{t}$ and not among the levels $\mathbf{x}_{t}$, serves to illustrate the importance of testing common factor restrictions rather than imposing them in multivariate I(1) systems.

\section{Conclusions.}

There are a number of extremely important implications for econometric modelling to be drawn from the analysis of the simple example in this paper.

1. Although it is important to test for serial correlation in the residuals of econometric models, it is rarely appropriate to 'autocorrelation correct' in response to rejecting the hypothesis of zero serial correlation.

2. Re-estimating a linear regression model by ALS imposes common factor restrictions, and inconsistent parameter estimates will result when the common factor restrictions are invalid. In fact, the example in section 2 illustrates such inconsistency even when the regression errors follow a first order autoregressive process!

3. The common factor restrictions imply very stringent constraints on the temporal structure of the variables being modelled, and as such are unlikely to hold in general. However, it is an empirical issue as to whether they are valid and so they should be tested, either directly (e.g. by using the COMFAC option within PC-GIVE), or indirectly via some of the sufficient conditions for them to hold.

4. The practice of 'autocorrelation correction' is an example of specific-to-general modelling, and so the example presented in section 2 is a particular illustration of the weaknesses of this modelling strategy. In contrast, a general-to-specific modelling strategy, which starts from a general congruent model and then tests for valid reductions of it, works impressively well. The general model $\mathrm{M}_{4}$ is congruent and is parsimoniously encompassed by $\mathrm{M}_{3}$, which is the data generation process for $y_{t} \mid z_{t}, z_{t-1}, y_{t-1}$. However, the static regression model $M_{1}$ and the ALS model $M_{2}$ are rejected as re- 
ductions of $\mathrm{M}_{4}$ and $\mathrm{M}_{3}{ }^{6}$

5. An important feature of the analysis is that the congruent general models $M_{4}$ and $M_{3}$ successfully explain the properties of models that are reductions of them. This illustrates that specification testing [in the sense of Mizon (1977a,b)], which is an essential feature of general-to-specific modelling, is a valid and effective way of modelling. Since $\mathrm{M}_{3}$ is the DGP for the conditional process $\mathrm{D}\left(y_{t} \mid z_{t}, x_{t-1}\right)$ it is not surprising that it has these properties. However, the overspecified model $M_{4}$ (it includes the irrelevant regressor $z_{t-1}$ in the conditional mean for $y_{t}$ ) correctly indicates that $M_{3}$ is a valid reduction, but that $M_{1}$ and $M_{2}$ are invalid reductions, of it. The weakness of the overspecified (but otherwise congruent) model $\mathbf{M}_{4}$ is not invalid inferences, but lack of efficiency in making valid inferences. This points to the value of incremental testing when there is a sequence of nested hypotheses, especially when it is an ordered sequence.

6. Given the importance of having congruent general models to provide a valid statistical framework for modelling, it is reassuring to note that the misspecification tests or diagnostic checking of models adopted in the paper powerfully indicated the inadequacy of noncongruent models. In particular, the residuals from $\mathbf{M}_{1}$ are revealed to be highly serially correlated.

7. The results obtained in the paper, using a sample of size 100 of artificially generated data for a very specific DGP, have been explained using asymptotic theory. In addition to explaining the inconsistency of ALS for the single sample of size 100 , the asymptotic theory for each statistic was seen to be in close agreement with the behaviour of the average of 10,000 Monte Carlo replications for these statistics. This strengthens the argument that 'autocorrelation correction' will lead to inappropriate inferences, since generally it imposes invalid restrictions.

8. COMFAC issues also arise in the analysis of nonstationary time series variables. Indeed, many of the univariate unit root test procedures commonly used in testing for cointegration (e.g. DF and ADF tests) impose common factors, and thus lack power

\footnotetext{
${ }^{6}$ In earlier versions of the paper, a first order autoregressive model for $y_{t}$, and the two COMFAC regression models associated with the bi-quadratic nature of the residual sum of squares for the Cochrane-Orcutt estimator, were also shown to be rejected strongly against both $M_{4}$ and $M_{3}$.
} 
against alternatives in which the common factor restrictions are invalid. Also the practice of applying filters to all variables prior to analyzing the relationship between them (e.g. differences) results in inefficient, and possibly inconsistent, inference when the implied common factor restrictions are invalid.

Hence, even for the simple example considered here, analysis of the relationship between the DGP and models of the data (both more general, and simpler, than the DGP) has yielded a number of valuable insights and proved to be especially rich in implications for econometric modelling.

Prepared for the International Conference on Bayesian and Classical Econometric Modelling of Time Series, GREQE, June 1992. The financial support for this research from the UK Economic and Social Research Council (ESRC grant R000233447) is gratefully acknowledged. The author is grateful to David Hendry for helpful discussions concerning the content of the paper, to Juan Dolado, Rob Engle, Clive Granger, and Ken Wallis, plus the members of the EUI Econometrics Research Workshop for their comments, and to Kristina Kostial for assistance in the preparation of the GAUSS programmes. Thanks are also due to Luc Bauwens and the referees for many valuable suggestions which helped to improve this version of the paper. 


\section{References}

Andrews, D.W.K., 1991, Heteroskedasticity and Autocorrelation Consistent Covariance Matrix Estimation, Econometrica 59, 817-858.

Banerjee, A., J. Dolado, J.W. Galbraith and D.F. Hendry, 1993, Co-Integration, Error-Correction, and the Econometric Analysis of Non-Stationary Data (Oxford University Press, Oxford).

Banerjee, A., D.F. Hendry and G.W. Smith, 1986, Exploring Equilibrium Relationships in Econometrics through Static Models: Some Monte Carlo Evidence, Oxford Bulletin of Economics and Statistics 48, 253-277.

Berndt, E.R., 1991, The Practice of Econometrics. Classic and Contemporary (Addison-Wesley, New York).

Box, G.E.P. and G.M. Jenkins, 1970, Time Series Analysis Forecasting and Control (Holden-Day, San Francisco).

Breusch, T.S., 1978, Testing for Autocorrelation in Dynamic Linear Models, Australian Economic Papers 17, 334-355.

Campos, J., N.R. Ericsson and D.F. Hendry, 1993, Cointegration Tests in the Presence of Structural Breaks, Board of Governors of the Federal Reserve System, International Finance Discussion Papers, No. 440.

Cochrane, D. and G.H. Orcutt, 1949, Application of Least Squares Regressions to Relationships Containing Autocorrelated Error Terms, Journal of the American Statistical Association 44, 32-61.

Davidson, R. and J.G. MacKinnon, 1993, Estimation and Inference in Econometrics, (Oxford University Press, New York).

Dickey, D.A. and W.A. Fuller, 1979, Distributions of the Estimators for Autoregressive Time Series with a Unit Root, Journal of the American Statistical Association $74,427-431$. 
Dickey, D.A. and W.A. Fuller, 1981, Likelihood Ratio Statistics for Autoregressive Time Series with a Unit Root, Econometrica 49, 1057-1072.

Doornik, J.A. and D.F. Hendry, 1992, PC-GIVE Version 7: An Interactive Econometric Modelling System (Oxford Institute of Economics and Statistics, Oxford).

Durbin, J., 1970, Testing for Serial Correlation in Least Squares Regression When Some of the Regressors are Lagged Dependent Variables, Econometrica 38, 410421.

Durbin, J. and G.S. Watson, 1950, Testing for Serial Correlation in Least Squares Regression I, Biometrika 37, 409-428.

Durbin, J. and G.S. Watson, 1951, Testing for Serial Correlation in Least Squares Regression II, Biometrika 38, 159-178.

Engle, R.F., 1984, Wald, Likelihood Ratio, and Lagrange Multiplier Tests in Econometrics, in: Z. Griliches and M.D. Intrilligator, eds., Handbook of Econometrics, Volume 2 (North-Holland, Amsterdam) 775-826.

Engle, R.F. and C.W.J. Granger, 1987, Co-Integration and Error Correction: Representation, Estimation and Testing, Econometrica 55, 251-276.

Engle, R.F., D.F. Hendry and J-F. Richard, 1983, Exogeneity, Econometrica 51, 277304.

Godfrey, L.G., 1978, Testing Against General Autoregressive and Moving Average Error Models When the Regressors Include Lagged Dependent Variables, Econometrica $46,1293-1302$.

Godfrey, L.G., 1990, Misspecification Tests in Econometrics (Cambridge University Press, Cambridge).

Granger, C.W.J., 1981, Some Properties of Time Series Data and Their Use in Econometric Model Specification, Journal of Econometrics 16, 121-130.

Granger, C.W.J., 1983, Forecasting White Noise, in: A. Zellner, ed., Applied Time Series Analysis of Economic Data (Bureau of the Census, Washington D.C.) 308314. 
Granger, C.W.J. and P. Newbold, 1974, Spurious Regressions in Econometrics, The Journal of Econometrics 2, 111-120.

Greene, William H., 1991, Econometric Analysis (MacMillan, New York).

Griffiths, W.E., R.C. Hill and G.G. Judge, 1993, Learning and Practicing Econometrics (Wiley, New York).

Hansen, B.E., 1991, A Comparison of Tests for Parameter Instability: An Examination of Asymptotic Local Power, mimeo., Economics Department, University of Rochester.

Hendry, D.F., 1983, Econometric Modelling: the Consumption Function in Retrospect, Scottish Journal of Political Economy 30, 193-220.

Hendry, D.F., 1987, Econometric Methodology: A Personal Perspective, in: T.F. Bewley, ed., Advances in Econometrics (Cambridge University Press, Cambridge) 29-48.

Hendry, D.F. and G.E. Mizon, 1978, Serial Correlation as a Convenient Simplification, not a Nuisance: a Comment on a Study of the Demand for Money by the Bank of England, Economic Journal 88, 549-63.

Hendry, D.F. and G.E. Mizon, 1990, Procrustean Econometrics: Or Stretching and Squeezing Data, in: C.W.J. Granger, ed., Modelling Economic Series, Readings in Econometric Methodology (Oxford University Press, Oxford) 1990, 121-136.

Hendry, D.F. and G.E. Mizon, 1993, Evaluation of Dynamic Econometric Models by Encompassing the VAR, in P.C.B. Phillips, ed., Models, Methods and Applications of Econometrics, Essays in Honor of Rex Bergstrom (Basil Blackwell, Oxford) $272-300$.

Hendry, D.F., A. Neale and N.R. Ericsson, 1990, PC-NAIVE: An Interactive Program for Monte Carlo Experimentation in Econometrics (Oxford Institute of Economics and Statistics, Oxford). 
Hoover, K.D. 1988, On the Pitfalls of Untested Common-Factor Restrictions: The Case of the Inverted Fisher Hypothesis, Oxford'Bulletin of Economics and Statistics 50, 125-138.

Hurwicz, L. 1950, Least Squares Bias in Time Series, in: T.C. Koopmans, ed., Statistical Inference in Dynamic Economic Models, Cowles Commission Monograph No.10 (Wiley, New York) 365-383.

Jarque, C.M. and Bera, A.K. (1980), Efficient Tests for Normality, Homoscedasticity and Serial Independence of Regression Residuals, Economics Letters 6, 255-259.

Johansen, S. 1988, Statistical Analysis of Cointegrating Vectors, Journal of Economic Dynamics and Control 12, 231-254.

Kremers, J.J.M, N.R. Ericsson, and J.J. Dolado, 1992, The Power of Cointegration Tests, Oxford Bulletin of Economics and Statistics 54, 325-348.

Mizon, G.E., 1977a, Model Selection Procedures in Dynamic Models, in: M.J. Artis and A.R. Nobay, eds., Studies in Modern Economic Analysis (Basil Blackwell, Oxford) $97-120$.

Mizon, G.E., 1977b, Inferential Procedures in Nonlinear Models: An Application in a UK Cross Section Study of Factor Substitution and Returns to Scale, Econometrica $45,1221-1242$.

Mizon, G.E., 1993, Empirical Analysis of Time Series: Illustrations with Simulated Data, in: A. de Zeeuw, ed., Advanced Lectures in Quantitative Economics II (Academic Press, New York) 184-205.

Newey, W.K. and K.D. West, 1987, A Simple Positive Semi-Definite Heteroskedasticity and Autocorrelation-Consistent Covariance Matrix, Econometrica 55, 703-708.

Sargan, J.D., 1964, Wages and Prices in the United Kingdom: A Study in Econometric Methodology, in: P.E. Hart, G. Mills and J.K. Whitaker, eds., Econometric Analysis for Economic Planning (Butterworths, London). Reprinted in: D.F. Hendry and K.F. Wallis, eds., 1984, Econometrics and Quantitative Economics (Basil Blackwell, Oxford) 275-314. 
Sargan, J.D., 1980, Some Tests of Dynamic Specification for a Single Equation, Econometrica $48,879-897$.

Spanos, A., 1986, Statistical Foundations of Econometric Modelling (Cambridge University Press, Cambridge).

Spanos, A., 1988, Error Autocorrelation Revisited: The AR(1) Case, Econometric Reviews 6, 285-294.

White, H., 1980, A Heteroskedasticity Consistent Covariance Matrix Estimator and a Direct Test for Heteroskedasticity, Econometrica 48, 817-838. 


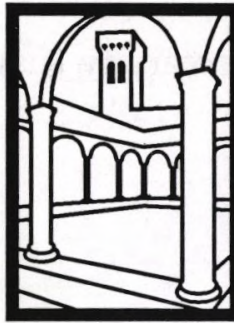

EUI

WORKING

PAPERS

EUI Working Papers are published and distributed by the

European University Institute, Florence

;

Copies can be obtained free of charge

- depending on the availability of stocks - from:

The Publications Officer

European University Institute

Badia Fiesolana

I-50016 San Domenico di Fiesole (FI)

Italy

Please use order form overleaf 


\section{Publications of the European University Institute}

To The Publications Officer

European University Institute

Badia Fiesolana

I-50016 San Domenico di Fiesole (FI) - Italy

Telefax No: $+39 / 55 / 573728$

From

Name

Address.

Please send me a complete list of EUI Working Papers

Please send me a complete list of EUI book publications

Please send me the EUI brochure Academic Year 1994/95

$\square$ Please send me the EUI Research Review

Please send me the following EUI Working Paper(s):

No, Author

Title:

No, Author

Title:

No, Author

Title:

No, Author

Title:

Date

Signature 


\section{Working Papers of the Department of Economics Published since 1990}

ECO No. 90/1

Tamer BASAR and Mark SALMON

Credibility and the Value of Information

Transmission in a Model of Monetary

Policy and Inflation

ECO No. 90/2

Horst UNGERER

The EMS - The First Ten Years

Policies - Developments - Evolution

ECO No. 90/3

Peter J. HAMMOND

Interpersonal Comparisons of Utility:

Why and how they are and should be made

\section{ECO No. 90/4}

Peter J. HAMMOND

A Revelation Principle for (Boundedly)

Bayesian Rationalizable Strategies

ECO No. 90/5

Peter J. HAMMOND

Independence of Irrelevant Interpersonal

Comparisons

ECO No. 90/6

Hal R. VARIAN

A Solution to the Problem of

Externalities and Public Goods when

Agents are Well-Informed

ECO No. 90/7

Hal R. VARIAN

Sequential Provision of Public Goods

ECO No. 90/8

T. BRIANZA, L. PHLIPS and J.F.

RICHARD

Futures Markets, Speculation and

Monopoly Pricing

ECO No. 90/9

Anthony B. ATKINSON/ John

MICKLEWRIGHT

Unemployment Compensation and

Labour Market Transition: A Critical

Review

ECO No. $90 / 10$

Peter J. HAMMOND

The Role of Information in Economics
ECO No. 90/11

Nicos M. CHRISTODOULAKIS

Debt Dynamics in a Small Open

Economy

ECO No. 90/12

Stephen C. SMITH

On the Economic Rationale for

Codetermination Law

ECO No. 90/13

Elettra AGLIARDI

Learning by Doing and Market Structures

ECO No. 90/14

Peter J. HAMMOND

Intertemporal Objectives

ECO No. 90/15

Andrew EVANS/Stephen MARTIN

Socially Acceptable Distortion of

Competition: EC Policy on State Aid

ECO No. 90/16

Stephen MARTIN

Fringe Size and Cartel Stability

ECO No. 90/17

John MICKLEWRIGHT

Why Do Less Than a Quarter of the

Unemployed in Britain Receive

Unemployment Insurance?

ECO No. 90/18

Mrudula A. PATEL

Optimal Life Cycle Saving With

Borrowing Constraints:

A Graphical Solution

ECO No. 90/19

Peter J. HAMMOND

Money Metric Measures of Individual and Social Welfare Allowing for

Environmental Externalities

ECO No. 90/20

Louis PHLIPS/

Ronald M. HARSTAD

Oligopolistic Manipulation of Spot

Markets and the Timing of Futures

Market Speculation 
ECO No. 90/21

Christian DUSTMANN

Earnings Adjustment of Temporary

Migrants

ECO No. 90/22

John MICKLEWRIGHT

The Reform of Unemployment

Compensation:

Choices for East and West

ECO No. 90/23

Joerg MAYER

U. S. Dollar and Deutschmark as

Reserve Assets

ECO No. 90/24

Sheila MARNIE

Labour Market Reform in the USSR:

Fact or Fiction?

ECO No. 90/25

Peter JENSEN/

Niels WESTERGÅRD-NIELSEN

Temporary Layoffs and the Duration of

Unemployment: An Empirical Analysis

ECO No. 90/26

Stephan L. KALB

Market-Led Approaches to European

Monetary Union in the Light of a Legal

Restrictions Theory of Money

ECO No. 90/27

Robert J. WALDMANN

Implausible Results or Implausible Data?

Anomalies in the Construction of Value

Added Data and Implications for Esti-

mates of Price-Cost Markups

ECO No. 90/28

Stephen MARTIN

Periodic Model Changes in Oligopoly

ECO No. 90/29

Nicos CHRISTODOULAKIS/

Martin WEALE

Imperfect Competition in an Open

Economy
米米米

ECO No. 91/30

Steve ALPERN/Dennis J. SNOWER

Unemployment Through 'Learning From

Experience'

ECO No. 91/31

David M. PRESCOTT/Thanasis

STENGOS

Testing for Forecastible Nonlinear

Dependence in Weekly Gold Rates of

Return

ECO No. 91/32

Peter J. HAMMOND

Harsanyi's Utilitarian Theorem:

A Simpler Proof and Some Ethical

Connotations

ECO No. 91/33

Anthony B. ATKINSON/

John MICKLEWRIGHT

Economic Transformation in Eastern

Europe and the Distribution of Income*

ECO No. 91/34

Svend ALBAEK

On Nash and Stackelberg Equilibria

when Costs are Private Information

ECO No. 91/35

Stephen MARTIN

Private and Social Incentives

to Form R \& D Joint Ventures

ECO No. 91/36

Louis PHLIPS

Manipulation of Crude Oil Futures

ECO No. 91/37

Xavier CALSAMIGJIIA/Alan KIRMAN

A Unique Informationally Efficient and

Decentralized Mechanism With Fair

Outcomes

ECO No. 91/38

George S. ALOGOSKOUFIS/

Thanasis STENGOS

Testing for Nonlinear Dynamics in

Historical Unemployment Series

ECO No. 91/39

Peter J. HAMMOND

The Moral Status of Profits and Other

Rewards:

A Perspective From Modern Welfare

Economics 
ECO No. 91/40

Vincent BROUSSEAU/Alan KIRMAN

The Dynamics of Learning in Mis-

Specified Models

ECO No. 91/41

Robert James WALDMANN

Assessing the Relative Sizes of Industryand Nation Specific Shocks to Output

ECO No. 91/42

Thorsten HENS/Alan KIRMAN/Louis PHLIPS

Exchange Rates and Oligopoly

ECO No. 91/43

Peter J. HAMMOND

Consequentialist Decision Theory and

Utilitarian Ethics

ECO No. 91/44

Stephen MARTIN

Endogenous Firm Efficiency in a Cournot

Principal-Agent Model

ECO No. 91/45

Svend ALBAEK

Upstream or Downstream Information Sharing?

ECO No. 91/46

Thomas H. McCURDY/

Thanasis STENGOS

A Comparison of Risk-Premium

Forecasts Implied by Parametric Versus

Nonparametric Conditional Mean

Estimators

ECO No. 91/47

Christian DUSTMANN

Temporary Migration and the Investment into Human Capital

ECO No. 91/48

Jean-Daniel GUIGOU

Should Bankruptcy Proceedings be

Initiated by a Mixed

Creditor/Shareholder?

ECO No. 91/49

Nick VRIEND

Market-Making and Decentralized Trade

ECO No. 91/50

Jeffrey L. COLES/Peter J. HAMMOND

Walrasian Equilibrium without Survival:

Existence, Efficiency, and Remedial

Policy
ECO No. 91/51

Frank CRITCHLEY/Paul MARRIOTT/

Mark SALMON

Preferred Point Geometry and Statistical Manifolds

ECO No. 91/52

Costanza TORRICELLI

The Influence of Futures on Spot Price

Volatility in a Model for a Storable

Commodity

ECO No. 91/53

Frank CRITCHLEY/Paul MARRIOTT/ Mark SALMON

Preferred Point Geometry and the Local Differential Geometry of the Kullback-

Leibler Divergence

ECO No. 91/54

Peter MØLLGAARD/

Louis PHLIPS

Oil Futures and Strategic

Stocks at Sea

ECO No. 91/55

Christian DUSTMANN/

John MICKLEWRIGHT

Benefits, Incentives and Uncertainty

ECO No. 91/56

John MICKLEWRIGHT/

Gianna GIANNELLI

Why do Women Married to Unemployed

Men have Low Participation Rates?

ECO No. 91/57

John MICKLEWRIGHT

Income Support for the Unemployed in Hungary

ECO No. 91/58

Fabio CANOVA

Detrending and Business Cycle Facts

ECO No. 91/59

Fabio CANOVAV

Jane MARRINAN

Reconciling the Term Structure of Interest Rates with the Consumption

Based ICAP Model

ECO No. 91/60

John FINGLETON

Inventory Holdings by a Monopolist

Middleman 
粰深

ECO No. 92/61

Sara CONNOLLY/John

MICKLEWRIGHT/Stephen NICKELL

The Occupational Success of Young Men

Who Left School at Sixteen

ECO No. 92/62

Pier Luigi SACCO

Noise Traders Permanence in Stock

Markets: A Tâtonnement Approach.

I: Informational Dynamics for the Two-

Dimensional Case

ECO No. 92/63

Robert J. WALDMANN

Asymmetric Oligopolies

ECO No. 92/64

Robert J. WALDMANN /Stephen

C. SMITH

A Partial Solution to the Financial Risk and Perverse Response Problems of Labour-Managed Firms: IndustryAverage Performance Bonds

ECO No. 92/65

Agustín MARAVALL/Víctor GÓMEZ

Signal Extraction in ARIMA Time Series

Program SEATS

ECO No. $92 / 66$

Luigi BRIGHI

A Note on the Demand Theory of the

Weak Axioms

ECO No. 92/67

Nikolaos GEORGANTZIS

The Effect of Mergers on Potential

- Competition under Economies or

Diseconomies of Joint Production

ECO No. $92 / 68$

Robert J. WALDMANN/

J. Bradford DE LONG

Interpreting Procyclical Productivity:

Evidence from a Cross-Nation Cross-

Industry Panel

ECO No. 92/69

Christian DUSTMANN/John

MICKLEWRIGHT

Means-Tested Unemployment Benefit and Family Labour Supply: A Dynamic Analysis
ECO No. 92/70

Fabio CANOVA/Bruce E. HANSEN

Are Seasonal Patterns Constant Over

Time? A Test for Seasonal Stability

ECO No. 92/71

Alessandra PELLONI

Long-Run Consequences of Finite

Exchange Rate Bubbles

ECO No. 92/72

Jane MARRINAN

The Effects of Government Spending on

Saving and Investment in an Open

Economy

ECO No. 92/73

Fabio CANOVA and Jane MARRINAN

Profits, Risk and Uncertainty in Foreign

Exchange Markets

ECO No. 92/74

Louis PHLIPS

Basing Point Pricing, Competition and

Market Integration

ECO No. 92/75

Stephen MARTIN

Economic Efficiency and Concentration:

Are Mergers a Fitting Response?

ECO No. 92/76

Luisa ZANCHI

The Inter-Industry Wage Structure:

Empirical Evidence for Germany and a

Comparison With the U.S. and Sweden

ECO NO. 92/77

Agustín MARAVALL

Stochastic Linear Trends: Models and

Estimators

ECO No. $92 / 78$

Fabio CANOVA

Three Tests for the Existence of Cycles in Time Series

ECO No. $92 / 79$

Peter J. HAMMOND/Jaime SEMPERE Limits to the Potential Gains from Market Integration and Other Supply-Side Policies 
ECO No. $92 / 80$

Víctor GÓMEZ and Agustín

MARAVALL

Estimation, Prediction and Interpolation

for Nonstationary Series with the

Kalman Filter

ECO No. 92/81

Víctor GÓMEZ and Agustín

MARAVALL

Time Series Regression with ARIMA

Noise and Missing Observations

Program TRAM

ECO No. 92/82

J. Bradford DE LONG/ Marco BECHT

"Excess Volatility" and the German

Stock Market, 1876-1990

ECO No. $92 / 83$

Alan KIRMAN/Louis PHLIPS

Exchange Rate Pass-Through and Market

Structure

ECO No. 92/84

Christian DUSTMANN

Migration, Savings and Uncertainty

ECO No. 92/85

J. Bradford DE LONG

Productivity Growth and Machinery

Investment: A Long-Run Look, 18701980

ECO NO. 92/86

Robert B. BARSKY and J. Bradford

DE LONG

Why Does the Stock Market Fluctuate?

ECO No. 92/87

Anthony B. ATKINSON/John

MICKLEWRIGHT

The Distribution of Income in Eastern

Europe

\section{ECO No.92/88}

Agustín MARAVALL/Alexandre

MATHIS

Encompassing Unvariate Models in

Multivariate Time Series: A Case Study

ECO No. $92 / 89$

Peter J. HAMMOND

Aspects of Rationalizable Behaviour
ECO 92/90

Alan P. KIRMAN/Robert

J. WALDMANN

I Quit

ECO No. 92/91

Tilman EHRBECK

Rejecting Rational Expectations in Panel

Data: Some New Evidence

ECO No. 92/92

Djordje Suvakovic OLGIN

Simulating Codetermination in a

Cooperative Economy

ECO No. 92/93

Djordje Suvakovic OLGIN

On Rational Wage Maximisers

ECO No. 92/94

Christian DUSTMANN

Do We Stay or Not? Return Intentions of

Temporary Migrants

ECO No. 92/95

Djordje Suvakovic OLGIN

A Case for a Well-Defined Negative

Marxian Exploitation

ECO No. 92/96

Sarah J. JARVIS/John

MICKLEWRIGHT

The Targeting of Family Allowance in Hungary

ECO No. 92/97

Agustín MARAVALLDaniel PEÑA

Missing Observations and Additive

Outliers in Time Series Models

ECO No. 92/98

Marco BECHT

Theory and Estimation of Individual and

Social Welfare Measures: A Critical

Survey

ECO No. 92/99

Louis PHLIPS and Ireneo Miguel

MORAS

The AKZO Decision: A Case of

Predatory Pricing?

ECO No. 92/100

Stephen MARTIN

Oligopoly Limit Pricing With Firm-

Specific Cost Uncertainty 
ECO No. 92/101

Fabio CANOVA/Eric GHYSELS

Changes in Seasonal Patterns: Are They

Cyclical?

ECO No. 92/102

Fabio CANOVA

Price Smoothing Policies: A Welfare

Analysis

棌米

ECO No. 93/1

Carlo GRILLENZONI

Forecasting Unstable and Non-Stationary

Time Series

ECO No. 93/2

Carlo GRILLENZONI

Multilinear Models for Nonlinear Time

Series

ECO No. 93/3

Ronald M. HARSTAD/Louis PHLIPS

Futures Market Contracting When You

Don't Know Who the Optimists Are

ECO No. 93/4

Alan KIRMAN/Louis PHLIPS

Empirical Studies of Product Markets

ECO No. 93/5

Grayham E. MIZON

Empirical Analysis of Time Series:

Illustrations with Simulated Data

ECO No. 93/6

Tilman EHRBECK

Optimally Combining Individual

Forecasts From Panel Data

ECO NO. 93/7

Víctor GÓMEZ/Agustín MARAVALL

Initializing the Kalman Filter with

Incompletely Specified Initial Conditions

ECO No. 93/8

Frederic PALOMINO

Informed Speculation: Small Markets

Against Large Markets

ECO NO. 93/9

Stephen MARTIN

Beyond Prices Versus Quantities
ECO No. 93/10

José María LABEAGAVAngel LÓPEZ

A Flexible Demand System and VAT

Simulations from Spanish Microdata

ECO No. 93/11

Maozu LU/Grayham E. MIZON

The Encompassing Principle and

Specification Tests

ECO No. 93/12

Louis PHLIPS/Peter MØLLGAARD

Oil Stocks as a Squeeze Preventing

Mechanism: Is Self-Regulation Possible?

ECO No. 93/13

Pieter HASEKAMP

Disinflation Policy and Credibility: The

Role of Conventions

ECO No. 93/14

Louis PHLIPS

Price Leadership and Conscious

Parallelism: A Survey

ECO No. 93/15

Agustín MARAVALL

Short-Term Analysis of Macroeconomic

Time Series

ECO No. 93/16

Philip Hans FRANSES/Niels

HALDRUP

The Effects of Additive Outliers on Tests

for Unit Roots and Cointegration

ECO No. 93/17

Fabio CANOVA/Jane MARRINAN

Predicting Excess Returns in Financial

Markets

ECO No. 93/18

Iñigo HERGUERA

Exchange Rate Fluctuations, Market

Structure and the Pass-through

Relationship

ECO No. 93/19

Agustín MARAVALL

Use and Misuse of Unobserved

Components in Economic Forecasting 
ECO No. 93/20

Torben HOLVAD/Jens Leth

HOUGAARD

Measuring Technical Input Efficiency for Similar Production Units:

A Survey of the Non-Parametric

Approach

ECO No. 93/21

Stephen MARTIN/Louis PHLIPS

Product Differentiation, Market Structure and Exchange Rate Passthrough

ECO No $93 / 22$

F. CANOVA/M. FINN/A. R. PAGAN

Evaluating a Real Business Cycle Model

\section{ECO No 93/23}

Fabio CANOVA

Statistical Inference in Calibrated Models

ECO No 93/24

Gilles TEYSSIÈRE

Matching Processes in the Labour Market in Marseilles. An Econometric Study

\section{ECO No 93/25}

Fabio CANOVA

Sources and Propagation of International Business Cycles: Common Shocks or Transmission?

\section{ECO No. 93/26}

Marco BECHT/Carlos RAMÍREZ Financial Capitalism in Pre-World War I Germany: The Role of the Universal Banks in the Financing of German Mining Companies 1906-1912

ECO No. 93/27

Isabelle MARET

Two Parametric Models of Demand, Structure of Market Demand from Heterogeneity

ECO No. 93/28

Stephen MARTIN

Vertical Product Differentiation, Intraindustry Trade, and Infant Industry Protection

ECO No. 93/29

J. Humberto LOPEZ

Testing for Unit Roots with the k-th Autocorrelation Coefficient
ECO No. 93/30

Paola VALBONESI

Modelling Interactions Between State and

Private Sector in a "Previously" Centrally Planned Economy

ECO No. 93/31

Enrique ALBEROLA ILA/J. Humberto LOPEZ/Vicente ORTS RIOS

An Application of the Kalman Filter to the Spanish Experience in a Target Zone (1989-92)

ECO No. 93/32

Fabio CANOVA/Morten O. RAVN

International Consumption Risk Sharing

ECO No. 93/33

Morten Overgaard RAVN

International Business Cycles: How much can Standard Theory Account for?

ECO No. 93/34

Agustín MARAVALL

Unobserved Components in Economic Time Series

ECO No. 93/35

Sheila MARNIE/John MICKLEWRIGHT

"Poverty in Pre-Reform Uzbekistan:

What do Official Data Really Reveal?"

ECO No. 93/36

Torben HOLVAD/Jens Leth

HOUGAARD

Measuring Technical Input Efficiency for Similar Production Units:

80 Danish Hospitals

ECO No. 93/37

Grayham E. MIZON

A Simple Message for Autocorrelation Correctors: DON'T 
